\title{
DEVELOPMENT OF METHODS OF POSITIONING, LOCALIZATION AND DATA COLLECTION FROM NODES OF A FREE MOBILE SENSOR NETWORK USING INTELLIGENT ADAPTIVE TELECOMMUNICATION AEROPLATFORMS
}

\author{
${ }^{1}$ Valery A. Romaniuk, ${ }^{2}$ Olexandr I. Lysenko, ${ }^{2}$ Valery I. Novikov, ${ }^{2}$ Ihor O. Sushyn \\ ${ }^{1}$ Military Institute of Telecommunications and Information Technologies named after \\ Heroes of Kruty, Kyiv, Ukraine \\ ${ }^{2}$ Institute of Telecommunication Systems \\ Igor Sikorsky Kyiv Polytechnic Institute, Kyiv, Ukraine
}

\begin{abstract}
Background. The article presents the results of a study of methods of positioning, localization and data collection from nodes of a mobile wireless sensor network using intelligent adaptive telecommunication air platforms. To implement the study of this research topic, an analysis of literary sources on this topic was carried out. Based on a fairly rich bibliographic material, this work has the main task of examining, analyzing and systematizing already known approaches to positioning objects in wireless sensor networks using intelligent adaptive telecommunication air platforms and suggesting options for their development.

Objective. The aim of the work is to improve the methods of direct data collection of TA from the nodes of BSM, the general directions of synthesis of which are defined in the work.

Methods. Methods of cluster analysis (network clustering), graph theory (research of analytical models of BSM with TA functioning, construction of cluster topology), theory of telecommunication networks (when calculating bandwidth in BSM with TA radio channels) and theory were used to solve the formulated problem. (when developing a positioning model for telecommunications air platforms)

Results. A technique for evaluating the effectiveness of methods for collecting data from wireless sensor networks using intelligent adaptive telecommunication air platforms is proposed.

Conclusions. The method of collecting TA monitoring data from the main nodes of clustered BSM has been improved. The method of estimation of efficiency of methods of data collection with BSM by telecommunication air platforms is offered.

Keywords: wireless sensor network; data collection method; network clustering; data exchange.
\end{abstract}

\section{Introduction}

Throughout the history of the development of science and technology, problems related to location determination have been encountered in a wide variety of fields: maritime navigation, radar, robotics, etc. In this case, the sequence of actions that the process of determining the coordinates of an object consists of usually consists in measuring in any way the relative position relative to landmarks, the coordinates of which are a priori known and the subsequent calculation of coordinates based on the information received. An example is the manual positioning procedure, which has been practiced for quite a long time, using a compass, a sectarian and stars.

Now the determination of the coordinates of objects in space is already usually determined automatically by means of special equipment based on the use of radio waves; in this case, artificially created buoys, lighthouses, satellites, etc. are used as landmarks. However, the very sequence of actions, the result of which is the determination of the coordinates of the object, remained the same.

The term "sensor network", having appeared relatively recently, is now a fairly well-established concept that has become widespread, and denotes a self-configuring network resistant to failure of individual elements, consisting of a large number of small, compact ones, and cheap semiconductor devices wirelessly connected to each other; network elements are not serviced and do not require special installation. Each node of the network can contain built-in sensors for physical parameters of the environment, for example, movement, level of humidity, light, 
temperature, pressure, etc., as well as microcircuits for primary processing of information and storage of received data. The number of nodes in a wireless sensor network (WSN) (Fig. 1) is actually determined only by the scope and financial constraints, and due to the low price of individual devices (from a few dollars and more) it can be very large (several thousand and more).

Wireless sensor networks (WSN) are increasingly used in various spheres of human activity [1]: monitoring the state of forests, agricultural fields, oil and gas pipelines, borders, environmental and meteorological monitoring of territories, search and rescue missions, etc.

A wireless sensor network can be designed to operate for months or even years in remote (inaccessible) areas in the absence of a public telecommunications infrastructure.

The only solution for collecting data from network nodes in these conditions is the use of telecommunication air platforms (TA), built on the basis of UAVs. Autonomous stationary sensor nodes monitor the specified parameters of the zones (objects) of their coverage, save the received data and, when a telecommunication air platform appears in their radio communication zone, transmit the collected data to it.

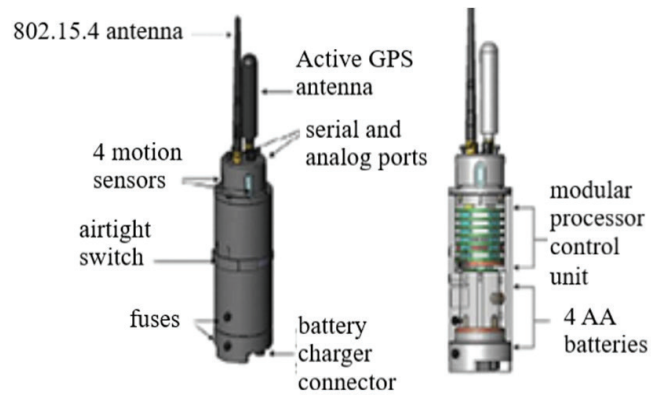

Fig. 1 - An example of the composition of the sensor node

Examples of wireless data transmission are technologies such as Wi-Fi, WiMAX, Bluetooth, EDGE, ZigBee. The choice of a particular technology depends, first of all, on the requirements for a particular network. The criteria can be bandwidth, frequency range, maximum number of nodes in the network, energy efficiency, etc. Comparative characteristics of some wireless technologies are presented in Table. 1.

Table 1 - Comparative characteristics of BlueTooth, Wi$\mathrm{Fi}$ and $\mathrm{ZigBee}$ technologies

\begin{tabular}{|c|c|c|c|}
\hline $\begin{array}{c}\text { Wireless } \\
\text { technology } \\
\text { (standard) }\end{array}$ & $\begin{array}{c}\text { ZigBee (IEEE } \\
802.15 .4)\end{array}$ & $\begin{array}{c}\text { Wi-Fi (IEEE } \\
802.11 \mathrm{~b})\end{array}$ & $\begin{array}{c}\text { Bluetooth } \\
\text { (IEEE } \\
802.15 .1)\end{array}$ \\
\hline $\begin{array}{c}\text { Frequency } \\
\text { range, GHz }\end{array}$ & $2,4-2,483$ & $2,4-2,483$ & $2,4-2,483$ \\
\hline $\begin{array}{c}\text { Bandwidth, } \\
\text { Kbps }\end{array}$ & 250 & 11000 & 723,1 \\
\hline
\end{tabular}

\begin{tabular}{|c|c|c|c|}
\hline $\begin{array}{c}\text { Protocol stack } \\
\text { size, Kbytes }\end{array}$ & $32-64$ & $>1000$ & $>250$ \\
\hline $\begin{array}{c}\text { Time of } \\
\text { continuous } \\
\text { autonomous } \\
\text { work from the } \\
\text { battery, days }\end{array}$ & $100-1000$ & $0,5-5$ & $1-10$ \\
\hline $\begin{array}{c}\text { The maximum } \\
\text { number of } \\
\text { nodes in the } \\
\text { network }\end{array}$ & 65536 & 10 & 7 \\
\hline $\begin{array}{c}\text { Range of } \\
\text { action, m }\end{array}$ & $10-100$ & $20-300$ & $10-100$ \\
\hline $\begin{array}{c}\text { Areas of } \\
\text { application }\end{array}$ & $\begin{array}{c}\text { Remote } \\
\text { monitoring and } \\
\text { management }\end{array}$ & $\begin{array}{c}\text { Transmission of } \\
\text { multimedia } \\
\text { information }\end{array}$ & $\begin{array}{c}\text { Wire } \\
\text { connection } \\
\text { replacement }\end{array}$ \\
\hline
\end{tabular}

Table 1 shows that the maximum number of nodes, as well as the longest battery life in the network of ZigBee technology, based on the IEEE 802.15.4 standard. This technology is also known as "Wireless Sensor Networks (WSN)" (WSN - Wireless Sensor Network).

Let's highlight the main features of this class of networks:

1. Lack of connectivity between network nodes or network fragments in the absence of public telecommunications infrastructure, which does not allow building classical schemes for collecting data in the WSN, based on the constructed transmission routes from sensor nodes to gateways (base stations).

2. The limited resources of both sensor nodes (with battery energy, processor performance, memory, transmitter power, radio channel capacity, etc.) and resources of telecommunication air platforms (in terms of time, altitude and flight speed, energy reserve, transmitter power, volume memory tee, etc.)

3. The dimension of the network is significant (hundreds, thousands of sensor nodes). Replacing batteries for such a large number of nodes may be impractical or even impossible. Therefore, reducing the energy consumption during data collection by the sensor nodes is critical to increasing the network uptime.

4. Delay in receiving monitoring data (DTN class). One of the ways to reduce the data collection time is network clustering and the definition of data collection points, which can significantly reduce the length of the flight path of the TA and, accordingly, reduce the data collection time.

The TA can collect data directly from each node in three main ways to fly the network:

1. Flight of the TA of each network node along the calculated route. The main advantages are the low energy consumption of the nodes for transmission, the simplicity of the algorithms for exchanging nodes with the TA (in the presence of radio communication with the TA, the sensor node transmits monitoring data) and, 
consequently, their low cost. The disadvantage is the significant flight time (data collection) of the aircraft, and, accordingly, the significant time for collecting monitoring data, increased requirements for its flight characteristics,

2. A flight of a TA over the entire territory of the network along the adopted trajectory (snake, spiral, etc.), which also requires a significant flight time and data collection and a large energy consumption of the nodes.

3. Flight by TA of data collection points. In this case, the network control center (or the control system of the telecommunications aerial platform during autonomous operation) splits it into clusters, calculates the position of the TA in space (in the form of points or trajectory intervals) to collect data from nodes in the clusters, and builds a flight route of only collection points. This method makes it possible to significantly reduce the time for collecting TA data, to reduce the energy consumption of the nodes' batteries, however, it implies the implementation of the corresponding algorithms for the interaction of the telecommunication air platform with the network nodes. The methods and algorithms for data collection proposed to date [2 - 6] solve only partial problems of data collection, do not take into account the peculiarities of the functioning of this class of networks, the multi-criteria nature of the target functions of network management and require improvement. Most of the works consider the flight of the TA over the entire monitoring area or consider clustering using the "centroid algorithm", according to which the data collection points are located in the area of the greatest concentration of nodes.

The aim of this work is to improve the methods of direct collection of TA data from the WSN nodes, the general directions of synthesis of which are defined in [7].

The object of research is the process of WSN functioning with the use of telecommunication aerial platforms for collecting monitoring data.

The subject of research is methods of collecting data over wireless sensor networks by telecommunication air platforms in the absence of a public telecommunications infrastructure.

Research methods. When solving the formulated problem, the methods of cluster analysis (when clustering a network), graph theory (when studying analytical models of indicators of the functioning of WSN with TA, building a cluster topology), theory of telecommunication networks (when calculating the bandwidth in radio channels WSN with TA) and optimization theory (when developing a model for positioning the position of telecommunication air platforms).

\section{Exposition}

One of the urgent problems is the determination of the location of individual objects of the WSN. An indispensable condition for the operation of any monitoring and control systems is the binding of data collected by the entire system to geographic coordinates for displaying the collected information on a map and subsequent analysis. In addition, such a network, unlike traditional radio networks, with a built-in subsystem for positioning individual objects, can be deployed almost anywhere with minimal costs. In addition to linking the data received by the network during operation to the terrain map, information about the coordinates of objects will be in demand during the operation of the network itself: building efficient routing algorithms in terms of energy consumption, collecting the collected data.

In this regard, the development of algorithms for determining the coordinates of objects in the sensor network becomes an urgent task. An example of existing coordinate determination systems is the RADAR system, invented by scientists Bahl and Padmanab. It is the first WLAN based positioning system. The RADAR system used the nearest neighbor algorithm and produced an average coordinate measurement error of 2.94 meters [8]. The error was reduced to 2.37 meters by improving the RADAR system with the Viterbi algorithm [9]. One of the best positioning systems available today is Ekahau (Ekahau Positioning Engine - EPE). Ekahau Positioning System is a real-time software based on the IEEE 802.11 network. EPE provides exact location, status and presence information for Wi-Fi tags and supported WiFi compatible devices. The elements of the Ekahau positioning system are shown in Fig. 2.

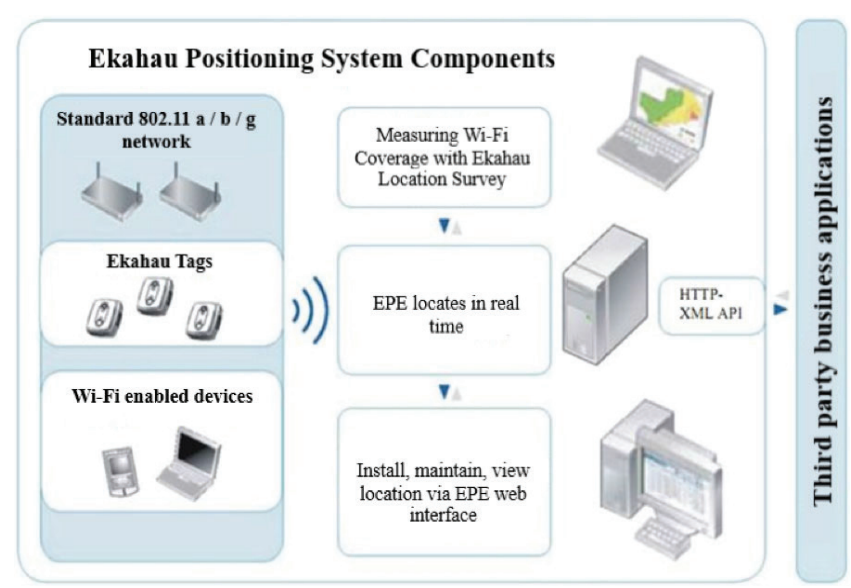


Fig. 2 - Components of the Ekahau positioning system

Ekahau wireless tags can be associated with identification information about the object being monitored, such as name or serial number, department, etc., as well as with application-specific parameters. These associations simplify the search for a selected object in a specific geographic area [10].

In an improved method for direct collection of monitoring data from nodes of a wireless sensor network with their clustering by telecommunication air platforms, the main stages of the synthesis of the method of direct data collection (MBZD) from WSN nodes with their TA clustering are proposed: determination of network clustering algorithms, construction of collection points for collection points, organization of the process exchange between nodes and TA (Fig. 3)

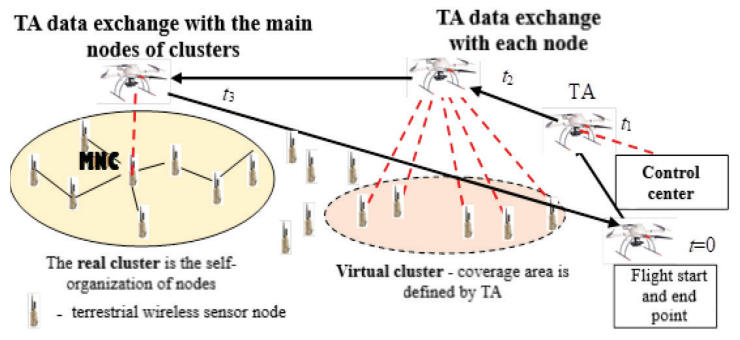

Fig. 3 - Illustration of methods for collecting data from TA nodes

The general statement of the problem is formulated.

Given: characteristics of WSN nodes and telecommunication air platforms: $\mathrm{N}$ - the number of stationary sensor nodes of the network and the coordinates of their location on the ground; NTA is the number of TA; V_dmi - volume of monitoring data of the $\mathrm{i}$-th node, $\mathrm{i}=\begin{array}{lll}1 & \ldots & \mathrm{N}\end{array}$; technical and telecommunication characteristics of ground sensor nodes, TA; each node of the network has its own control system, operates in cooperation with TA (with other nodes).

It is necessary to: determine the number and coordinates of data collection points, the procedure for collecting monitoring data from the WSN nodes by telecommunication air platforms and the trajectory of their movement (positioning), in order to perform certain target control functions (CF): minimizing or ensuring the time of data collection (1), maximizing or ensuring a certain operating time (Top) WSN (2), minimization or use of a given amount (NTA) TA (3)

$\mathrm{Tdc} \rightarrow \min$ or $\mathrm{Tdc} \leq \mathrm{Td}$ degiv,

Top $\rightarrow$ min or Top $\geq$ Topgiv,

NTA $\rightarrow$ min or NTA $\leq$ NTAgiv,

$$
\begin{aligned}
& \mathrm{Tdc}=\mathrm{Lfl} / \mathrm{v} ; \mathrm{Lbfl}=\mathrm{f}(\mathrm{nk},(\mathrm{x}, \mathrm{y}) \mathrm{k}, \mathrm{h}, \mathrm{St}), \\
& \mathrm{k}=1 \ldots \mathrm{nk}, \\
& \text { subject to the constraints } \Omega \text { on: }
\end{aligned}
$$

time limit (route length $\mathrm{L}$ ) in a round of TA flight -

Tdc $\leq$ Tpolmax $(0<\mathrm{Lmb} \leq \mathrm{Lmr} \leq \mathrm{Lmmax})$;

TA flight speed $-\mathrm{v}=[\mathrm{vmin}, \mathrm{vmax}]$; the number of clusters $-1 \leq \mathrm{k} . \leq \mathrm{nk}$;

battery energy of nodes and TA - ei $\leq$ emax, eTA $\leq$ eTAmax;

location coordinates $(\mathrm{x}, \mathrm{y})$ of nodes in the monitoring area;

flight altitude of TA $-\mathrm{h}=[\mathrm{hmin}, \mathrm{hmax}]$; radio communication range $d \leq d \max$;

the size of the buffers of the nodes and TA Vbufwuzi $\leq$ Vbufwuzah; VbufTA $\leq$ VbufTamah;

requirements of service models (guaranteed quality of service - the flight time of each k-th cluster tobklk must be greater than the total transmission time between all nodes and the TA - tobklk $\geq$ tperk);

$\mathrm{St}$ - the set of strategies (rules) for flying around the cluster.

The data collection time (expression 5) depends on the length of the flight route, determined by the number and location of data collection points, the speed of the TA, while satisfying the node transfer time for the chosen strategy of flying around the clusters. Fig. 4 shows a variant of flying over a TA of 5 clusters when collecting monitoring data from certain collection points.

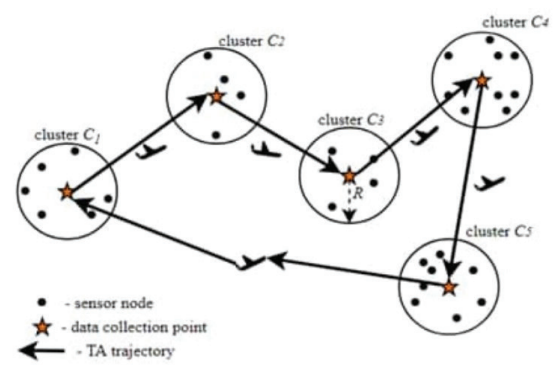

Fig. 4 - Variant of movement TA between data collection points

To minimize the number of collection points, it is necessary to minimize the number of clusters

$$
\text { Min K, }
$$

when the restrictions are fulfilled:

$$
\min _{y_{1}, y_{2,}, \cdots, y_{K}} \max _{j} \min _{x \in C_{j}}\left|x-y_{k}\right| \leq d_{\max }, k=\overline{1, K}, j=\overline{1, J},
$$$$
\mathrm{K} \leq \mathrm{Kmax}, \mathrm{R}=[\mathrm{Rmin} . . . \mathrm{Rmax}], \mathrm{h}=[\mathrm{hmin} . .
$$
hmax],

where $|\mathrm{x}-\mathrm{y}|$ is the Euclidean distance between points $\mathrm{x}$ and $\mathrm{y}$ on the ground, qj is the number of sensor nodes in the $\mathrm{j}$-th cluster. Inequality (8) - the maximum 
distance between the center of the coverage area and the sensor nodes should be minimized; inequality (9) determines the limiting number of nodes in clusters; (10) - sets resource constraints.

The problem belongs to the class of NP-complete, it is difficult to obtain an exact solution for large-scale networks, therefore, to solve it, it is necessary to use heuristic methods. For temporary network clustering, it is proposed to use TA as the main cluster node, which implements (in contrast to the existing centroid algorithms) modified iterative FOREL (FORmal ELement) cluster analysis algorithms and k-means that find the minimum (or specified) number of data collection points in the network.

The basic route of flying around the data collection points (its length $\mathrm{Lmb}$ ) is constructed according to one of the known methods for constructing the shortest path (solving the traveling salesman problem), for example, by the method of finding the nearest neighbor, which has insignificant computational complexity and is close to optimal solutions.

For flying around cluster nodes, rules for adjusting the base flight route are proposed, taking into account the priority of certain target network management functions (expressions $1-3$ ).

Analytical models are proposed for assessing the time for collecting TA data from network nodes, which make it possible to plan the trajectory of movement and evaluate the effectiveness of the decisions made.

The total time of flight (data collection) of all nodes $\mathrm{j}=1 \ldots \mathrm{J}$ (or data collection points) in the cluster should be minimal. Then

$$
T_{\mathrm{dc}}=\sum_{j=1}^{J-1} t_{\mathrm{fl} j, j+1} / v_{j, j+1} \rightarrow \min
$$

where tpr - flight time TA all nodes of the cluster, $\mathrm{v}$ - flight speed.

$$
\begin{aligned}
& t_{\mathrm{fl} j} \geq t_{\mathrm{ne} j}=s\left(d, \Pi_{\mathrm{kffl}}\right) /\left(V_{\mathrm{dm} j}\right), \\
& t_{\mathrm{p} j}=t_{\mathrm{cj}}+t_{\mathrm{oj} j}+t_{\mathrm{opj} .}
\end{aligned}
$$

The transmission time ttransj consists of the following intervals: establishment of connection tvsvj (exchange of service messages), waiting for transmission tпрj (according to the protocol of multiple access to the channel) and transmission of monitoring data tbperj (the transmission rate $\mathrm{s}$ in the radio channel depends on the distance $\mathrm{d}$ between the node and the TA, protocols (pkf) channel and physical layers). The data exchange time must exceed the lifetime of the radio channel during the flight of the TA over this node (12). Therefore, the flight altitude of a TA is determined taking into account the target control functions and restrictions on its resources.

A generalized algorithm for the implementation of the method of direct collection of monitoring data from
WSN nodes by telecommunication air platforms is proposed, which is shown in Fig. 5.

It allows you to shorten the flight route and, accordingly, the data collection time by minimizing the number of clusters (monitoring data collection points); increase the network operating time by reducing the transmission power between the TA and sensor nodes, adapting the coverage radius of the TA, finding the closest exchange points to the route of the TA, building energy efficient data transmission routes between the cluster nodes and the TA.

To evaluate the results of the functioning of the method, its software implementation in the MATLAB environment was carried out.

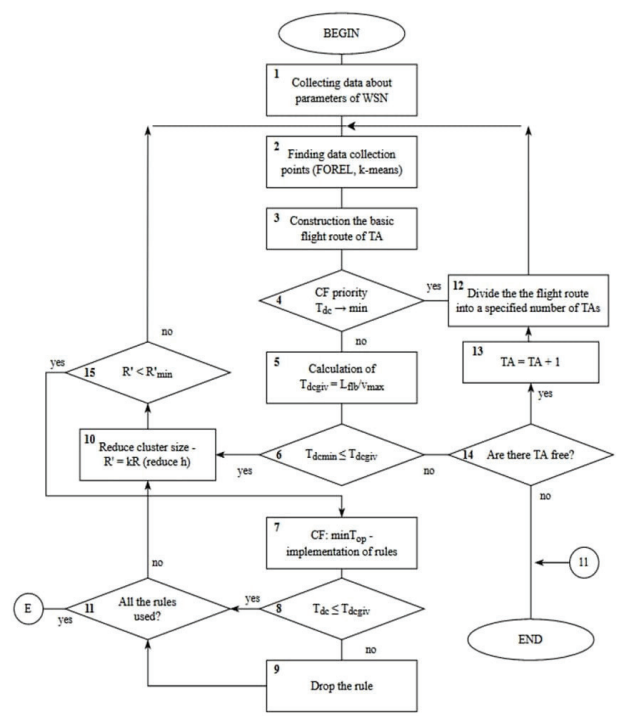

Fig. 5 - Scheme-algorithm for implementing the method of direct collection from WSN using TA

Experiments and acquired dependencies were carried out: the time of data collection, the time of stable operation of the network on the dimension of the network, the number of nodes in the cluster when using different methods of data collection.

An assessment of the effectiveness of the application of the improved method of direct data collection from the WSN TA has been carried out. It allows you to gain a $10-15 \%$ gain in network monitoring data collection time (due to a decrease in data collection points) and increase the network operation time (due to new rules for flying around nodes in clusters) by $12-17 \%$ compared to the existing centroid methods of direct data collection having negligible computational complexity $\mathrm{O}\left(\mathrm{n}^{2}\right)$.

A method is considered for collecting monitoring information from the WSN nodes, which is divided into clusters with the formation of the main cluster nodes (GIC) $[11,12,13$ - 17, 18, 19 - 31]. The nodes self- 
organize, build and maintain the cluster topology, data transfer routes from the monitoring nodes to the GIK, which receive and save the monitoring data of the nodes of their cluster until the TA arrives. The TA flies around the GIK (or chooses another flight strategy), which, when establishing radio communication with the TA, transmit to it the monitoring data of the cluster nodes. Fig. 6 shows the options for clustering the network when using various metrics for choosing the GIK. The advantages of this method in comparison with the method of direct data collection from WSN TA nodes are a significant reduction in the time for collecting monitoring information and a smaller number of TA required for data collection. However, this method requires the development and implementation of additional network control algorithms that increase the requirements for the hardware and software of the WSN nodes and add additional service traffic.
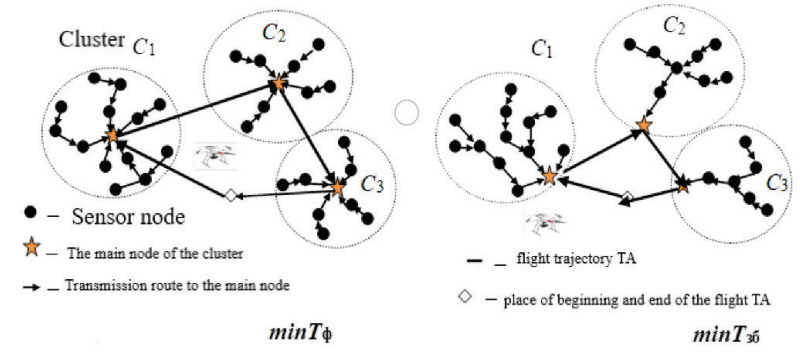

Fig. 6 - Variants of network clustering for different target management functions

The number and size of clusters affects the time for collecting TA information, battery power consumption (network operation time), volume of service traffic, transmission delay, etc. To solve the clustering problem, an iterative algorithm is proposed for finding a feasible solution - the required number of clusters in the network that satisfy the objective functions (1) and (2). Its main idea is that if ncl increases, then Tdc increases and Top increases and vice versa. The algorithm tries to satisfy the constraints and obtain feasible solutions.

The basis of the algorithm is an analytical model of the energy consumption of the i-th node ei under various operating modes (reception, transmission, data monitoring, sleep): $e_{i}=e_{\mathrm{r} i}+e_{\mathrm{tr} i}+e_{\mathrm{dm} i}+e_{\mathrm{sl}}$, which makes it possible to predict the energy consumption of the nodes in one round of a selection of strategies for flying around clusters to achieve certain target management functions. The number of rounds of operation (operation time) of the network is equal to $N R$ $=e_{i 0} / e_{i}$, where ei0 is the initial energy of the i node.

If NR> NRset, then the WSN satisfies the requirement for the operation time and you can optimize the data collection time.
Let's take a closer look at the model.

Each node transmits data to the main cluster node (GCM) via router nodes. The total volume of exchange data is: the volume of monitoring data Vmon of each node transmitted by each node to the MNC along the constructed routes, the volume of service data Vsl in the cluster, determined by the accepted exchange protocols at different levels of the OSI model.

Energy consumed by a simple node: monitoring and transmission of MNC monitoring data through a neighboring node $\mathrm{j}$ is carried out, sleep mode:

$e_{i \text { simple }}=e_{i \mathrm{dm}}+e_{\mathrm{trij}} V_{\mathrm{dm} i}+e_{\mathrm{r} j i} V_{\mathrm{r} j}+e_{\mathrm{s}}, e_{\mathrm{tr} i j}$ $=\alpha+\beta r_{i j}^{2}$,

where epr and eperij are the energy spent on the bit of receiving and transmitting data, Vr, Vtr are the volumes of transmitted and received data; $\alpha, \beta$ are coefficients, rij is the distance between nodes $\mathrm{i}$ and $\mathrm{j}$.

The energy consumed by the relay node in the route from a simple source node $s$ to the MNC-q: s-... -j-i-b... -q:

$$
e_{\text {iret }}=e_{i s i m p l e}+\left(e_{\mathrm{rij}} V_{\mathrm{dms}}+e_{\mathrm{trij} j} V_{\mathrm{tri} i}+e_{\mathrm{trib}} V_{\mathrm{dms}}+\right.
$$

$\left.e_{\mathrm{rb} i} V_{\mathrm{np} b}\right) n_{\mathrm{n} 3}$,

where $\mathfrak{I}$ is the set of nodes-sources of the subtree of the route to the MNC through i.

The energy expended by the q-th main node of the k-th cluster - eqMNCk: reception-transmission from $\mathrm{TA}$; receiving monitoring data $\mathrm{Vdmi}$ from all cluster nodes through the $\mathrm{j}$-th neighbors; transmission of confirmation to neighboring nodes; aggregation of data from all cluster nodes; building the topology of this; construction of transmission routes for emarsh; building clusters eklast; dream:

$$
\begin{gathered}
e_{q \mathrm{MNC} k}=e_{\mathrm{r} q-\mathrm{TA}} V_{\mathrm{rTA}}+e_{\mathrm{tr} q-\mathrm{TA}} n_{\mathrm{n} k} V_{\mathrm{dm} i}+e_{\mathrm{r} q j}\left(n_{\mathrm{n} k}-1\right) V_{\mathrm{dm} i}+ \\
+e_{\mathrm{tr} q j}\left(n_{\mathrm{n} k}-1\right) V_{\mathrm{tr} i j}++e_{\mathrm{agr} q} n_{\mathrm{n} k} V_{\mathrm{dm} i}+e_{\mathrm{top}}+e_{\mathrm{m}}+e_{\mathrm{c}}+
\end{gathered}
$$

$e_{\mathrm{dm}}+e_{\mathrm{sl}}$,

where erq-TA and etrq-TA are the energy consumed per bit during reception and transmission between the q-th MNC-TA, eagr is the energy spent on data aggregation, erqj, etrqj is the energy consumption for receiving $\mathrm{MNC}$ information from neighboring sensors, nnkk Is the number of nodes in the cluster, $j$ is the neighbor node of node $i$.

In contrast to the well-known clustering algorithms (LEACH, EEHC, HEED, DWEHC, etc.), the proposed algorithm determines the GCI using sets of metrics:

$\mu 1$ is the level of residual energy of the node battery (priority of CF - max Top); 
$\mu 2$ is the distance between the GCC to the TA (priority of the CF - min Tdc);

$\mu 3$ is the number of neighboring nodes at the node;

$\mu 4$ is the distance from the node to the main node of the cluster;

$\mu 5$ is the number of retransmissions from the node to the main node of the cluster.

The main idea: at the planning stage of data collection, the priority in the choice of metrics when forming clusters will be determined by the network management system based on the priority of target management functions (Zy $\rightarrow \mu \mathrm{y})$. Fig. 7 shows the result of BCM clustering when applying the priority of certain control CFs (metrics). Building a cluster topology that meets the target management functions.
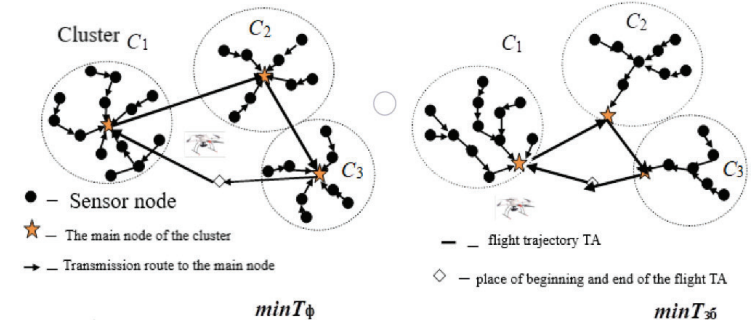

Fig. 7 - The result of clustering for different target management functions

An improved algorithm for managing the topology of WSN clusters is proposed based on the rules for forming RNG and Gabriel graphs, which allow building energy-efficient cluster topologies in real time. Application of the proposed algorithm allows saving up to $20 \%$ of the energy of cluster nodes. It is proposed to use a probe coordinate routing algorithm that builds and maintains transmission routes depending on the target control functions by using a variety of metrics for choosing data transmission routes from monitoring nodes to the MNC (energy consumed by a node for transceiving, residual battery energy, number of retransmissions, distance in GIK and their convolutions). A certain set of metrics is used depending on the current target function of network management.

A generalized algorithm has been developed for the implementation of an improved method for collecting monitoring data from the main nodes of TA, which implements a set of control algorithms: a network control center, TA, main cluster nodes, router nodes and monitoring nodes.

Experiments and the obtained dependencies were carried out: the time of data collection, the time of stable operation of the network on the dimension of the network with a different number of flights of the TA when using different algorithms for collecting data from the TA with the GIK.

It is shown that the improved method for collecting monitoring data from TA with GIK allows guaranteed service of nodes, reducing the time for collecting monitoring data by an average of $14 \%$, and increasing the network operation time by $10-15 \%$ in comparison with existing methods of data collection.

Evaluation of the effectiveness of methods for collecting data on wireless sensor networks by telecommunication air plaToporms - an appropriate assessment method is presented that combines a set of analytical models for assessing the time of the WSN operation, the time for collecting monitoring data with a simulation model of the functioning process of the monitoring data collection subsystem of the control system B.

Using the developed models in the MATLAB environment, studies of efficiency indicators (data collection time, BCM operation time, etc.) of improved monitoring data collection methods were carried out in comparison with existing ones for various initial data: network dimension $\mathrm{N}$, number of clusters, number of nodes in a cluster nk etc.

The simulation results of the improved method of direct data collection from the WSN TA nodes in comparison with the existing centroid algorithms of the corresponding class demonstrated a $10-15 \%$ gain in network monitoring data collection time (due to a decrease in data collection points) and an increase in the network operation time by $12-17 \%$ (fig. 8 ).
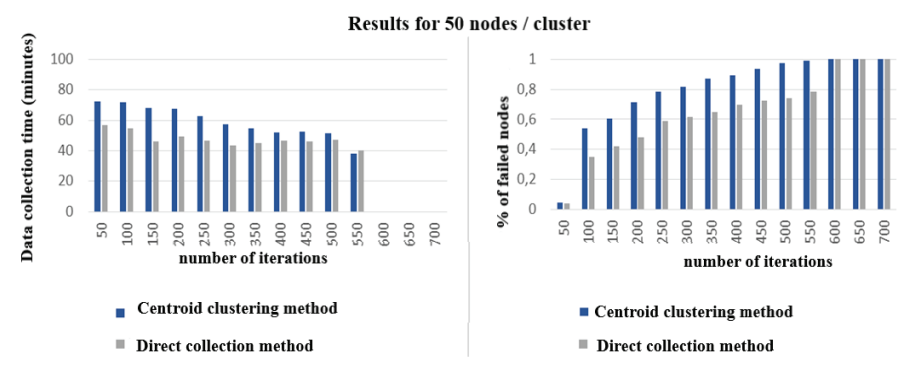
50

Fig. 8 - Dependences Tdc, Top at $\mathrm{N}=400$ and $\mathrm{nk}=$

The simulation results of the improved method for collecting TA data from the main nodes of the clustered network in comparison with the well-known method of clustering WSN HEED showed a decrease in the time for collecting monitoring data by an average of $14 \%$, an increase in the network operation time by $10-15 \%$. (Fig. 9) 


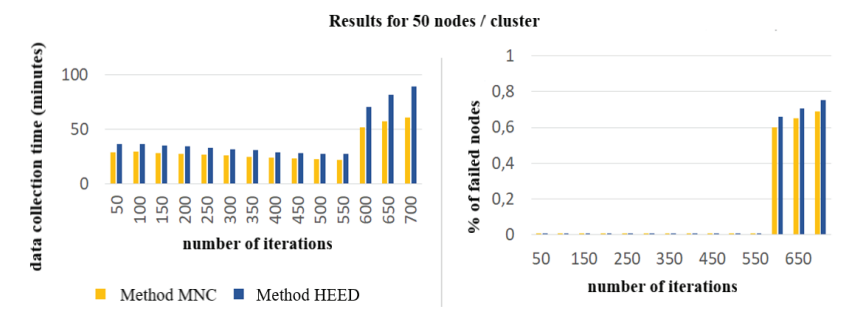
50

Fig. 9 - Dependences Tdc, Top at $\mathrm{N}=400$ and $\mathrm{nk}=$

\section{Conclusions}

The method of collecting monitoring data from the main nodes of the clustered WSN has been improved. The difference between the developed method and the known ones is that for the first time new approaches to network clustering have been proposed (a new set of metrics for choosing the main nodes to achieve certain target functions for managing the collection of monitoring data, the use of improved rules for finding energy-efficient cluster topologies by the directional enumeration method when using the probe coordinate routing method in a cluster, which makes it possible to reduce the monitoring data collection time by an average of $14 \%$, to increase the network operation time by $10-15 \%$ in comparison with the existing data collection methods of the corresponding class.

A technique for evaluating the effectiveness of data collection methods with WSN telecommunication air plaToporms is proposed.

The essence of the methodology is that it is proposed to combine a set of analytical models for assessing the time of functioning of the WSN, the time of collecting monitoring data with a simulation model of the process of functioning of the subsystem for collecting monitoring data of the control system of the WSN.

Using the developed models, studies of efficiency indicators (time of data collection, time of operation of the WSN, etc.) of improved methods of collecting monitoring data were carried out in comparison with the existing ones with different initial data: network dimension, number of clusters, number of nodes in a cluster, etc. The practical significance of the results obtained is that the developed methods, mathematical models and algorithms allow:

determinning the trajectory (position) of telecommunication air platforms for collecting monitoring data from the WSN to achieve various target network management functions in real time;

planning the trajectory of movement of the TA for the exchange of data with the network nodes;

increasing the efficiency of algorithmic and mathematical support of the network control system.

\section{References}

1. Dan Popescu, Florin Stoican, Grigore Stamatescu, Oana Chenaru and Loretta Ichim A Survey of Collaborative UAV-WSN Systems for Efficient Monitoring. Sensors 2019, 19 (21), 4690, retrieved from https://doi.org/10.3390/s19214690.

2. Imad Jawhar, Nader Mohamed, Jameela Al-Jarood. UAV-based data communication in wireless sensor networks: Models and Strategies. International Conference on Unmanned Aircraft Systems (ICUAS), 2015.

3. Huseyin Okcu, Mujdat Soyturk. Distributed Clustering Approach for UAV Integrated Wireless Sensor Networks. International Journal of Ad Hoc and Ubiquitous Computing, 2014, Vol.15, No. 1-3, pp. 106 -120 .

4. Dac-Tu Ho, Esten Ingar Grotli, and Tor Arne Johansen Heuristic Algorithm and Cooperative Relay for Energy Efficient Data Collection with a UAV and WSN. Retrieved from http://folk.ntnu.no/torarnj/ho_2013.pdf.

5. Cheng Zhan, Yong Zeng, Rui Zhang. EnergyEfficient Data Collection in UAV Enabled Wireless Sensor Network // IEEE Wireless Communications Letters, Volume: PP, Issue 99, 2017.

6. Romaniuk A. Method of the date collecting in wireless sensor networks with unmanned aerial vehicles. Collection of scientific papers MITI. Kyiv. 2018. № 1. pp. 90 - 99.

7. Romaniuk A.V. Synthesis of data collection methods by telecommunication airplatforms in wireless sensors networks / A.V. Romaniuk, V.A. Romaniuk, O.I. Lysenko, M.K. Sparavalo, O.V. Zhuk // Information and Telecommunication Sciences. - № 2. - 2020. - pp. $63-73$.

8. Bahl P., Padmanabhan V.N. RADAR: An in-building RF-based user location and tracking system// Proceedings of the 19th Annual Joint Conference of the IEEE Computer and Communications Societies. $784 \mathrm{p}$.

9. Bahl P., Padmanabhan V. N., Balachandran A. Enhanncements to the RADAR User Location and Tracking System// Microsoft Research: Redmond, WA. 2000, $784 \mathrm{p}$.

10. Ekahau positioning engine 4.6; 802.11 based wireless LAN positioning system"/ An Ekahau Technology Document, November 2009. 55 p. [Electronic resource]. Retrieved from URL: file://E:/Downloads/klodevil/User\%20Guide.pdf. Appeal date 20.11.19.

11. A. V. Romanyuk Algorithm for temporal clustering of wireless sensor network nodes for collecting monitoring information using UAVs / A.V. Romanyuk 
// Intermediate science and technology collection "Adaptive systems and automatic control", No. 2 (33). 2018 .-- pp. 106 - 117. https://doi.org/10.20535/15608956.33.2018.164680.

12. Lysenko O. Optimal control of telecommunication airoplatform in the area of emergency / O. Lysenko, S. Valuiskyi, P. Kirchu, A. Romaniuk // Telecommunication Sciences. - 2013. - vol. 4. - № 1. pp. $14-20$.

13. Zhuk O.V. Analysis of topology control methods in wireless sensor networks / O.V. Zhuk, A.V. Romanyuk, D.V. Tkachenko // Collection of scientific works of VITI. - 2017. - No. 2. - pp. 41 - 47.

14. Zhuk O.V. Models of building coverage and target detection in wireless sensor networks / O.V. Zhuk, A.V. Romanyuk, V.V. Tarasov, D.V. Tkachenko // Collection of scientific works of VITI. - 2017. - No. 3. pp. $41-48$.

15. Lysenko O.I. Methods for assessing the performance indicators of radio stations from telecommu- nications aeroplatforms / O.I. Lysenko, S.V. Valuyskiy, A.V. Romanyuk // Scientific Bulletin of the Academy of Municipal Management. Series: Technics. - 2013. - No. 6. - pp. 46 - 61.

16. Strela T.S. Analysis of routing methods in wireless sensor networks / T.S. Strela, O.V. Zhuk, A.V. Romanyuk // Collection of scientific works of VITI № 3. - 2017. - pp. 66 - 75 .

17. V. A. Romanyuk Approaches to the development of a new architecture for a control system for heterogeneous wireless sensor networks / V.A. Romanyuk, E.I. Lysenko, I. V. Alekseeva, A.V. Romanyuk, V.I. Novikov // Mathematical machines and systems, - 2017. - No. 2. - pp. 15 - 23, RSCI. ISSN 1028-9763.

18. A. V. Romanyuk Classification of tasks of the control system of an episodic radio network based on telecommunication air platforms / A.V. Romanyuk, S.V. Valuisky, O. I. Lysenko // Collection of materials of the international scientific and technical conference "Problems of telecommunications" PT-2015. Kiev. 2015 .-- pp. 381 - 383.

19. Amin Shahraki, Amir Taherkordi, Øystein Haugen, Frank Eliassen Clustering objectives in wireless sensor networks: A survey and research direction analysis. June 2020. Computer Networks 180:107376. DOI: 10.1016/j.comnet.2020.107376.

20. Heinzelman, W.R., Chandrakasan, A., Balakrishnan, H. Energy-Efficient Communication Protocol for Wireless Microsensor Networks, Proceedings of the 33rd International Conference on System Sciences (HICSS '00), Jan.2000.
21. Bandyopadhyay, S., Coyle, E.J., An Energy Efficient Hierarchical Clustering Algorithm for Wireless Sensor Networks, INFOCOM Twenty-Second Annual Joint Conference of the IEEE Computer and Communications, Vol. 3, pp. 1713 - 1723, 2003.

22. Younis, O., Fahmy, S., Distributed Clustering in Ad-hoc Sensor Networks: A Hybrid, Energy-Efficient Approach, Proceedings of IEEE INFOCOM, 2004.

23. Ping Ding, Joanne Holliday, Aslihan Çelik, „Distributed Energy-Efficient Hierarchical Clustering for Wireless Sensor Networks", Proceedings of the IEEE International Conference on Distributed Computing in Sensor Systems, pp. 322 - 339, 2005.

24. Fazackerley, S., Paeth, A., Lawrence, R., „Cluster Head Selection Using RF Signal Strength”, Proceedings of Canadian Conference on Electrical and Computer Engineering, pp. 334 - 338, 2009.

25. Pantziou G., Mpitziopoulos, A., Gavalas, D., Konstantopoulos, C., Mamalis, B. Mobile Sinks for Information Retrieval from Cluster-Based WSN Islands, Proceedings of the 8th International Conference on Ad-Hoc, Mobile and Wireless Networks (ADHOCNOW'09), pp. 213 - 226, 2009.

26. J. Pan. Topology Control for Wireless Sensor Networks / J. Pan, Y. T. Hou, L. Cai, Y. Shi, S. X. Shen // In proceedings of ACM Mobicom'03. - 2003.

27. Y. Xu. Geography-informed Energy Conservation for Ad Hoc Routing / Y. Xu, J. Heidemann, D. Estrin // In proceedings of ACM Mobicom. - 2001.

28. B. Chen. Span: An Energy-Efficient Coordination Algorithm for Topology Maintenance in Ad Hoc Wireless Networks / B. Chen, K. Jamieson, H. Balakrishnan, R. Morris // In proceedings of Mobicom. $-2001$.

29. Lysenko A.I., Romanyuk V.A., Guida E.G., Dvorskaya S.V., Osinsky A.K. Conceptual approach to ensuring the functional vibility of the wireless sensor measures I. Vernadsky. Series: Engineering Sciences. 2021. - No. 32, part 1. - pp. 10-16.

30. Romanyuk V.A., Lysenko A.I., Romanyuk A.V., Novikov V.I., Guida O.G., Method of collecting information from wireless sensor network nodes using intellectual financials Vernadsky. Series: Engineering Sciences. - 2021. - No. 32, part 2. - pp. 25-35.

31. Lysenko O.I., Tachinina E.M., Novikov V.I., Guida O.G., Sushin I.A. Theoretical bases for designing the motion control of distributed information and telecommunication work // Scientific notes of V.I. Vernadsky. Series: Engineering Sciences. - 2021. - No. 32, part 3. - pp. 55-62. 
Романюк В. А, Лисенко О.I, Новіков В.I, Сушин I.O.

Розвиток методів позиціонування, локалізації та збору даних із вузлів бездротової мобільної сенсорної мережі з використанням інтелектуальних адаптивних телекомунікаційних аероплатформ

Проблематика. У статті наведено результати дослідження методів позиціонування, локалізації та збору даних 3 вузлів мобільної бездротової сенсорної мережі з використанням інтелектуальних адаптивних телекомунікаційних повітряних платформ. Для реалізації дослідження цієї теми дослідження було проведено аналіз літературних джерел на цю тему. Грунтуючись на досить багатому бібліографічному матеріалі, основне завдання даної роботи - вивчити, проаналізувати та систематизувати вже відомі підходи до позиціювання об'єктів у бездротових сенсорних мережах 3 використанням інтелектуальних адаптивних телекомунікаційних повітряних платформ та запропонувати варіанти їх розвитку.

Мета. Метою роботи є вдосконалення методів прямого збору даних ТА з вузлів БСМ, загальні напрямки синтезу яких визначено у роботі.

Методи. Для вирішення сформульованої задачі були використані методи кластерного аналізу (кластеризація мережі), теорії графів (дослідження аналітичних моделей функціонування БСМ з ТА, побудова топології кластера), теорії телекомунікаційних мереж (при розрахунку пропускної спроможності в радіоканалах БСМ з ТА) та теорії (під час розробки моделі позиціонування телекомунікаційних повітряних платформ)

Результати. Пропонується методика оцінки ефективності методів збору даних із бездротових сенсорних мереж за допомогою інтелектуальних адаптивних телекомунікаційних повітряних платформ.

Висновки. Удосконалено метод збору даних моніторингу ТА з основних вузлів кластеризованих БСМ. Запропоновано метод оцінки ефективності методів збору даних із БСМ телекомунікаційними повітряними платформами.

Ключові слова: бездротова сенсорна мережа; метод збирання даних; кластеризація мережі; обмін даними.

Романюк В. А, Лысенко А.И, Новиков В.И, Сушин И.А.

Развитие методов позиционирования, локализации и сбора данных с узлов беспроводной мобильной сенсорной сети с использованием интеллектуальных адаптивных телекоммуникационных аэроплатформ

Проблематика. В статье представлены результаты исследования методов позиционирования, локализации и сбора данных с узлов мобильной беспроводной сенсорной сети с использованием интеллектуальных адаптивных телекоммуникационных воздушных платформ. Для реализации исследования данной темы исследования был проведен анализ литературных источников по данной теме. Основываясь на достаточно богатом библиографическом материале, основная задача данной работы - изучить, проанализировать и систематизировать уже известные подходы к позиционированию объектов в беспроводных сенсорных сетях с использованием интеллектуальных адаптивных телекоммуникационных воздушных платформ и предложить варианты их развития.

Цель. Целью работы является усовершенствование методов прямого сбора данных ТА с узлов БСС, общие направления синтеза которых определены в работе.

Методы. Для решения сформулированной задачи были использованы методы кластерного анализа (кластеризация сети), теории графов (исследование аналитических моделей функционирования БСС с ТА, построение топологии кластера), теории телекоммуникационных сетей (при расчете пропускной способности в радиоканалах БСС с ТА) и теории (при разработке модели позиционирования телекоммуникационных воздушных платформ)

Результаты. Предлагается методика оценки эффективности методов сбора данных из беспроводных сенсорных сетей с помощью интеллектуальных адаптивных телекоммуникационных воздушных платформ.

Выводы. Усовершенствован метод сбора данных мониторинга ТА с основных узлов кластеризованных БСС. Предложен метод оценки эффективности методов сбора данных с БСС телекоммуникационными воздушными платформами.

Ключевые слова: беспроводная сенсорная сеть; метод сбора данных; кластеризация сети; обмен данными. 